\title{
MODERNIDAD, HISTORICIDAD Y CONSTRUCCIÓN DE TERRITORIALIDADES DESDE UN PASAJE-MUNDO. El ESTRECHO DE MAGALLANES TRAS SU “DESCUBRIMIENTO"
}

MAURICIO ONETTO P. ${ }^{a}$

\section{RESUMEN ${ }^{1}$}

Este artículo analiza la importancia otorgada en términos geopolíticos, históricos y espaciales al descubrimiento del estrecho de Magallanes y a la empresa de la primera vuelta a la Tierra, dirigida inicialmente por Fernando de Magallanes y finalizada al mando de Sebastián Elcano. Para ello, se estudian las informaciones que aporta el primer documento oficial que se efectúa tras este viaje que es considerado como un acontecimiento global. Se trata de la carta escrita por Maximilian Transylvanus en 1522, en la que se describe una serie de aprehensiones que superan la dimensión geográfica o, únicamente cartográfica, del descubrimiento de este estrecho que denominamos pasaje-mundo. El texto exhibe un punto de quiebre con lo que era la conciencia histórica, espacial y territorial de la época en Europa. Asimismo, se examina cómo el estrecho de Magallanes, desde su hito fundante, sirvió como una referencia territorial para articular otras referencias de índole real e imaginaria.

PALABRAS CLAVE: Estrecho de Magallanes, conciencia-mundo, monstruosidad, historicidad, modernidad, territorialidades del secreto.

\section{MODERNITY, HISTORICITY AND THE CONSTRUCTION OF TERRITORIALITIES FROM A WORLD- PASSAGE. THE STRAIT OF MAGELLAN AFTER ITS "DISCOVERY"}

\footnotetext{
ABSTRACT

This article analyzes the importance given in geopolitical, historical and spatial terms to the discovery of the Strait of Magellan and to the first circumnavigation voyage, initially led by Ferdinand Magellan, but completed under the command of Sebastian Elcano. For this purpose the information provided by the first official document produced after this trip, where the voyage is considered as a global event is studied. This document is a letter written by Maximilian Transylvanus in 1522; it describes a series of details going beyond

1 Este artículo es parte de una investigación más amplia que aborda la relevancia del estrecho de Magallanes en la configuración territorial de Chile y América en el siglo XVI, la

cual es financiada por CONICYT, FONDECYT de INICIACIÓN $\mathrm{N}^{\circ}$ 11150474. Agradecemos los comentarios y sugerencias hechas por el Dr. Andrés Vélez Posada a este texto

a Docente-Investigador de la Universidad Autónoma de Chile. mauricio.onetto@uautonoma.cl
} 
the geographic or merely cartographic dimension of the discovery of this strait, which I call world-passage. The document reflects a breaking point in what was the European historical, spatial and territorial consciousness at that time. By the same token, how the Strait of Magellan served, from the very moment of its discovery, as a landmark to articulate other real or imaginary territorial references is studied.

KEY WORDS: Magellan Strait, consciousness-world, monstrosity, historicity, modernity, territorialities of secret.

El estrecho que con tantos trabajos habian buscado era este ciertamente, aunque ellos por entonces no lo sabian certificadamente, como después que por él pasaron, lo vieron y conoscieron. Duróles por mas de veinte y cinco leguas este estrecho $y$ en algunas partes hallaron que era de anchura de tres y cuatro leguas, en otra de una y dos leguas, y que en algunas partes no tenia si no poco mas de media legua, y que se iba siempre encorbando y volviendo hacia la parte occidental. (Transylvanus, 1522, p. 275).

En el año 1522, Maximilianus Transylvanus era secretario de Carlos $\mathrm{V}$ en Valladolid ${ }^{2}$. Desde esa localidad escribió una carta en latín a Matthaüs Lang, Arzobispo de Salzburgo y también obispo de Cartagena, quien se encontraba en Nuremberg junto a Francisco Chericati, obispo de Abruzzo, en una misión política-económica de asistencia al Reichstag encomendada por el Papa Adriano VI. La carta se tituló originalmente Maximiliani Transyluani Caesaris a Secretis Epistola, de Admirabili \& Nouissima Hispanoru[m] in Orientem Nauigatione, Qua Uariae, \& Nulli Prius Accessae Regiones Inue[n]tae Sunt, Cum Ipsis Etia[m] Moluccis Insulis

2 Transylvanus era discípulo de Pedro Mártir de Anglería y estaba casado con Francisca de Haro, sobrina de Cristóbal de Haro, socio de Fernando de Magallanes en la expedición que descubrió el Estrecho. Véase (Castro, 2007, p. 883).

3 Una de las versiones más utilizadas de este documento es la de Martín Fernández de Navarrete: "Maximiliano Transylvanus de cómo y por quién y en qué tiempo fueron descubiertas y halladas las islas Malucas, donde es el nascimiento de la especiería, las cuales caen en la conquista y marcación de la Corona Real de España. E divídese esta relación en veinte párrafos principales. 5 de octubre de 1522”. Esta versión que se encuentra en el tomo IV de la Colección de documentos inéditos de ultramar, fue mejorada por José Toribio Medina posteriormente y por ello es la que ocupamos en este estudio. Luego de la primera traducción, cada editor modificó
Beatissimis, Optimo Aromatu[m] Genere Refertis: Inauditi Quoq. Incolar[um] Mores Exponutur, Ac Multa Quae Herodotus, Plinius, Solinus Atque Alii Tradiderunt, Fabulo Sa Esse Arguunt. Contra, Nonnulla Ibide[m] Uera, Uix Tamen Credibilia Explicant. Quibuscum Historiis Insularibus Ambitus Descrebit Alterius Hemisphaerii, Unde Ad Nos Tande [m] Hispani Redierunt Incolumes ${ }^{3}$.

La misiva, que posteriormente se reimprimió en distintas partes de Europa ${ }^{4}$, fue recibida en el mes de noviembre en Alemania y en ella se informaba que, gracias a la expedición dirigida por Fernando de Magallanes, España poseía nuevas tierras: las afamadas y verdaderas islas Molucas, que de acuerdo a esta reciente expedición y a lo acordado en el Tratado de Tordesillas, ahora le pertenecían. No obstante, este no fue el único dato relevante. La carta presentó un nuevo pasaje desde donde se podía acceder a Oriente, el que, posteriormente, se denominó estrecho de Magallanes.

Este escrito constituyó el primero de una serie de documentos referidos a la expedición. Poco tiempo después, aparecieron los testimonios de Pigafetta y de otros de los marinos de aquella compañia 5 . En paralelo, la corte española se vio obligada a reforzar una serie de disposiciones normativas, capitulaciones militares, reales provisiones y a

el nombre del documento con tal de promover su lectura (Medina, 1888, p. XXIV-XXVII). Para otras precisiones sobre la carta, veáse (Benites, 2013, p. 202).

4 Uno de los primeros escritos posteriores que se pueden vincular con la carta de Transylvanus, que habla sobre algunos pormenores del viaje de Magallanes y Elcano, es el de Pietro Martire d'Anghiera (1530). En especial el capítulo septimum, de la quinta década. Ver también las transcripciones hechas por (Pigafetta, 1993; Bergreen, 2005; Castro, 2007).

5 Uno de los primeros escritos posteriores que se pueden vincular con la carta de Transylvanus, que habla sobre algunos pormenores del viaje de Magallanes y Elcano, es el de Pietro Martire d'Anghiera (1530). En especial el capítulo septimum, de la quinta década. Ver también las transcripciones hechas por (Pigafetta, 1993); (Bergreen, 2005); (Castro, 2007). 
crear medidas capitulares que no existían ${ }^{6}$, para mantener equilibrados los intereses de aquellos privados que conservaban numerosas conquistas en diferentes partes del, para ese entonces, $\mathrm{Globo}^{7}$. Este escrito, que se podría definir como un relato de viaje ${ }^{8}$ o relación de sucesos, constituyó una oficialización del descubrimiento del estrecho de Magallanes ${ }^{9}$. Sin embargo, poco se sabe de cómo fue recibido por el resto de los reinos europeos en una época en donde los conflictos políticos, económicos y sociales estaban latentes entre ellos. Quizás fue el secretismo sobre las navegaciones en esos años y el posible conocimiento previo de aquella zona (Dickson, 2007), por parte de los portugueses, lo que provocó este hermetismo. Lo que sí se conoce bastante son los efectos posteriores que este descubrimiento provocó, y que derivó en un replanteamiento general de la geopolítica mundial (Sallamann, 2003). En efecto, gracias a este hecho ambas potencias colonizadoras de esos años, Portugal y España, se enfrascaron en disputas diplomáticas en torno al Tratado Tordesillas -el cual tocaba tanto las nuevas tierras del Nuevo Mundo como las tierras asiáticas-, lo que desembocó finalmente en un cambio en la distribución de los territorios a nivel planetario con el Tratado de Zaragoza en $1529^{10}$.

\section{REFUTACIÓN DE LO ANTIGUO, DESDE UN NUEVO MUNDO E HISTORICIDAD}

El paso de las naos dirigidas por Fernando de Magallanes por el Estrecho provocó una revolución a

6 Por ejemplo, ver los documentos del Archivo General de Indias, sección CHILE, Audiencia de Chile, 165, L1, L2, L3.

7 Besse (2003) comenta que la visión global terrestre no comenzó a operar de inmediato, sino posteriormente ( $p$. 110); en relación a la doctrina de la esfera, su evolución y reticencias antes y después de la primera circunnavegación, ver el trabajo de (Dekker, 2001-2002); Cf. Buisseret (2003).

8 Sobre esta idea y una reflexión sobre la estructura de los párrafos del documento, ver: (Benites, 2013). Para ella, La escritura supone entonces un proceso de sedimentación en tanto acopio interpretativo sobre un mismo suceso (p. 203).

9 Como señala Jean-Marc Besse (2003), la idea de descubrimiento en esos tiempos era una no- vedad en la medida que ya había una discusión instaurada. Su idea original señala lo siguiente: l'expérience de la découverte n'apporte sa nouveauté que dans la mesure où celle-ci peut être mise en scène dans les formes d'une ancienne discussion des opinions. (p. 53); Sloterdijk (2004), indica escala global. Desde Valladolid se sabía del impacto político que producirían en Europa las noticias aportadas por esta travesía. Fue por esta razón que el documento se ideó desde una dimensión propagandística que auguraba proyectos de expansión económica-territorial y universalidad para Carlos V. No obstante, creemos que la propaganda política no apuntó directamente a las cortes, sino a los sostenedores, económicos -banqueros, comerciantes, marinos, etc., como culturales, científicos, universidades, etc. ${ }^{11}$, de la Monarquía.

En términos geopolíticos, el escrito no ocultó la relevancia de la expedición ni del paso de esta por el extremo sur de América. Al contrario, propuso que este viaje se definiera como el más importante de la historia, puesto que habría roto el monopolio de comprensión del espacio que había construido el mundo antiguo a lo largo de los siglos. La distinción con lo antiguo fue repetitiva en el texto y con ello se buscó diferenciar lo hecho por Elcano y los marinos sobrevivientes -solamente 18- de aquellos célebres navegantes que desde la Antigüedad habían sido los referentes náuticos a quienes admirar ${ }^{12}$. La vuelta a Sevilla debía ser desde ahora considerada como el mayor logro náutico de la historia ${ }^{13}$ :

Son por cierto estos diez y ocho marineros que con esta nao aportaron a Sevilla mas dignos de ser puestos en inmortal memoria, que aquellos argonautas que con Jason navegaron y fueron a Colchides, de quien

algo similar: no es ningún azar histórico-lingüístico que hasta el siglo XVI la palabra "descubrir" [entdecken] no significara literalmente otra cosa que quitar una cobertura de encima de un objeto, es decir, destapar algo conocido, y que sólo después adoptara el sentido de hallazgo de algo desconocido (p. 786).

10 El documento original de este tratado se encuentra en Archivo General de Indias, PATRONATO, 49, R.9; también existe una referencia dentro de la carta sobre el Tratado de Tordesillas, veáse (Medina, 1888, p. 260).

11 Con respecto a cómo funcionaba la conciencia propagandística durante el siglo XV e inicios del siglo XVI, ver (Carrasco, 1998, p. 230, 246). Cf. Nieto (1999); (García, 2011).

12 Para Emmanuelle Vagnon (2010), esto se debió en parte a la influencia del humanista florentino Cristoforo Buondelmonti.

13 Para entender la importancia de los puertos españoles en términos de geopolítica y comercio durante estos años, ver (BénatTachot, 2015). 
los antiguos poetas hacen tanta celebridad. E mucha más digna cosa es por cierto, que esta nuestra nao sea colocada y ensalzada entre las estrellas que la en que navegó aquel griego; pues que aquella navegó desde Grecia solamente por la mar del Ponto, y esta partiendo de Sevilla contra el mediodía, y dando de alli vuelta contra el occidente, dando con diversas reflexiones a todo el globo e orbe de la tierra e agua, volvió a Sevilla de donde primero había partido (Transylvanus, 1522, p. 297)

Gracias a la expedición, definitivamente se había podido instalar una certitud global desde el punto de vista de la medición. El paso por el estrecho de Magallanes era la consolidación de una nueva forma de percibir y transitar por el Mundo. Por primera vez, la imagen que soportaba todas las otras imágenes se había completado. La Tierra como planeta, tanto en su dimensión geográfica como cosmográfica, encontró sus referencias finales para definirse desde distintos ámbitos y escalas: desde la astrología hasta en términos geopolíticos. Como indica Jean-Marc Besse (2003): Au sein de la géographie du XVIe siècle se développe un concept de la Terre où celleci est à la fois pensé, décrite, imaginée et percue comme Terre universelle, comme Surface partout habitable, indéfiniment parcourable, ouverte dans toutes les directions (p. 18).

Ciertos párrafos dentro de esta extensa comunicación nos permiten verificar cómo desde este escrito se quiso hacer patente un antes y un después en referencia a múltiples temas, siendo uno de ellos el de la medición planetaria. Con respecto a esto último, el documento ilustró el momento en que Fernando de Magallanes y el mercader Cristóbal de Haro presentaron su viaje al Rey, indicando que algunos cálculos que se tenían como referencias estaban incorrectos. Uno de los argumentos que esgrimieron ambos aventureros para motivar a que la Corona auspiciara esta empresa, fue afirmar que territorios como Malaca - a partir de las informaciones

14 Sobre el impacto de Ptolomeo en el siglo XV véase (Hiatt, 2008).

15 En 1459, Fray Mauro de Venecia había replanteado algunos de los postulados de Ptolomeo. (Freedman, 2010, pp. 207208).

16 La importancia de las especias no fue conservar la comida, que poseían- se encontraban dentro de la partición de Castilla y no de Portugal, como lo estaba hasta entonces. No obstante, a pesar del conocimiento que tenían tanto desde su propia experiencia como desde las múltiples fuentes que nutrieron sus apreciaciones, no lograron convencer a la corte, porque aún no se había hallado hasta entonces la razón cierta de las medidas de la longitud del mundo (Transylvanus, 1522, p. 262).

La tensión aumentó tras la vuelta al globo. La certitud apareció como una negación a las mediciones esbozadas por estudiosos como Tolomeo ${ }^{14}$, quien solamente había podido establecer un cálculo real sobre la mitad de lo que era realmente el planeta ${ }^{15}$ :

E como quiera que los cosmógrafos y mayormente el Tolomeo pusieron en sus dimensiones diciendo, que desde las Canarias, yendo hacia el oriente hasta Catigarán, había $180^{\circ}$ de longitud, que es la mitad de toda la longitud del globo de la tierra y agua, habían segun aquella dimensión antigua de hallar y medir en esta navegacion que agora hicieron los nuestros (yendo como fueron por esta otra parte del occidente, y volvieron por el oriente) otros $180^{\circ}$ hasta el Catigarán para el cumplimiento de los $360^{\circ}$ que hay en toda la longitud; no empero pudieron mensurar aquestos ni poner señales ni términos por donde pudiesen hacer muy cierta esta medida, según las grandes reflexiones y vueltas que fueron haciendo para buscar el pasage que buscaban par entrar en el otro mar del sur (Transylvanus, 1522, p. 265).

Esta variación al mundo conocido también quedó patentada desde los primeros párrafos del documento, por medio del replanteamiento sobre el origen de la propia especería ${ }^{16}$, de lo que se creía era el más allá conocido hasta aquel entonces, los propios límites del mundo. La carta muestra desde sus inicios que la zona que se pensaba que era

como se ha transmitido desde hace décadas, sino más bien entregar un conjunto de sensaciones, olores, concepciones de salud, prestigio, prácticas culinarias y de moda con las que estaban asociadas. Ver el trabajo de (Freedman, 2010). Un trabajo que aborda la idea de capitalismo y deseo que forjaron las especias, es el de Timothy Morton (2000). 
de donde se sacaba la especería no correspondía verdaderamente al lugar sindicado durante siglos, sino a un lugar que se hallaba más allá de las demarcaciones transitadas, más lejano y aún incógnito -no descubierto- para los europeos ${ }^{17}$, un mundo extraño:

fuesen a aquel mundo extraño, y por tantos siglos jamas hasta agora sabido, a buscar y descubrir las islas en las cuales es el propio nascimiento de la especiería. Porque aunque los portugueses hayan hasta agora traido y trayan a estas nuestras partes grande abundancia de especias de la Aurea Chersonesa, que creemos ser Malaca; no empero nasce ni se cria en aquella India Oriental del Rey de Portugal otra especia, salvo pimienta. Ca tenemos por cierto y sabemos que las otras especias de canela, clavos y nueces moscadas y macias, que es un operimento o tela que tienen encima las nueces moscadas, a quien por otro nombre llamamos flor moscada, son traídas a aquella India oriental de unas islas muy lejanas e apartadas de allí, e tan solamente conoscidas par nombre a los indios de Malaca. (Transylvanus, 1522, p. 257)

El texto proponía constantemente que todo lo que se había escrito y creído desde la Antigüedad era en cierta medida falso ${ }^{18}$, gracias a las informaciones dejadas por esta nueva experiencia de tránsito ${ }^{19}$ que contradecían lo que habían escrito

17 Alfred Hiatt (2008) estudia profundamente el cambio que se produjo en el siglo XVI con la noción de lo incógnito. Para él: The Unknown was not only present, but fundamental to the map's statement of geographical knowledge on the move: Terra Australis was land not simply 'unknown', but 'not yet known (p.2).

18 Al respecto Carrasco precisa: La desautorización nos habla de una propaganda negativa o entendida desde el punto de vista de lo negativo (porque es la propaganda que emplea el adversario), pero, igualmente, en los textos aparecen términos que pueden expresar la propaganda que podríamos denominar positiva, la cual se corresponde con la que promueve el propio autor emisor. (Carrasco, 1998, p. 249).

19 Para Besse (2003), gracias a este tipo de descubrimiento comenzó una reivindicación del valor de la experiencia connotados pensadores al respecto:

Cierto es y claramente vemos segun agora nos muestra la experiencia que todas las cosas que los antiguos escriptores nos dejaron escriptas cerca de las tierras y provincias del propio suelo donde nasce y se cria la especiería, en parte son fabulosas $y$ en parte tan agenas de la verdad (...) solamente digo: que Erodocto, autor clarísimo, tiene que la canela se halla y coge de los nidos de las aves; la cual dice que traen de muy longincas regiones para hacer sus nidos, e que mayormente se halla en el del ave fénix; el cual nido no sé yo si jamas lo haya persona alguna visto. E el Plinio que se pensaba decir alguna cosa mas cierta por haber ya sido antes de su edad sabidas y verificadas muchas tierras y mares, ansí con las flotas del grande Alejandro, como de otros, tiene que la canela nasce y se cria en la Etiopia, que está junta a los Trogloditas: como se nos haya agora descubierto en contraria de aquello ser el suelo de su propio nascimiento muy longísimo y muy remoto de toda la Etiopía y mayormente de los Trogloditas que habitan en cuevas soterráneas (Transylvanus, 1522, p. 258)20.

La fuente exhibe un cambio respecto a lo que se había comprendido como verdadero en el tiempo ${ }^{21}$. El documento apuntaba a una nueva forma de entrelazar verdad e historia desde la experiencia de circulación y territorialidades descubiertas. La experiencia de aquel presente no sólo validaba

como la Fuente legítima para conocer el mundo. (pp. 70 y ss); Cf. Grafton (1995).

20 Desde este punto de vista, nos parecen sugerentes las consideraciones de Louise Bénat-Tachot (2001): On voit donc que la force des modèles épistémologiques modèle les regards et construit l'intelligibilité des expériences nouvelles (p. 69).

21 Con esto queremos señalar que se instaló el deseo de traducir y ordenar las experiencias del tiempo -las maneras de articular el pasado, presente y futuro- de otra manera, para así darles un nuevo sentido. (Hartog, 2003, p. 147). En este sentido, nuestra reflexión toma la pregunta de Koselleck sobre ¿cómo en cada presente, las dimensiones temporales del pasado y futuro han sido puestas en relación? (1990, p. 11). 
discursivamente como verdad los territorios revelados, sino que solicitaba que se dejara de creer en lo que espacialmente había dado soporte a los antiguos para establecer sus ideas ${ }^{22}$, como se observa en el caso de la isla Trapobana, situada en el Océano Indico ${ }^{23}$ : Ca es de saber que en el lugar que el Tolomeo y el Plinio $y$ los otros cosmógrafos pusieron la Tropabana, no hay agora allí islas que pueda por razón alguna ser creida la Traprobana (Transylvanus, 1522, p. $261)^{24}$.

El cambio que acusamos está relacionado con una consciencia moderna. Las palabras del secretario de Estado son una declaración de que una nueva era se había instalado y nos advierten la relación que se puede establecer entre su aparición y el descubrimiento del Estrecho. La Modernidad la entendemos en este caso como una apertura temporal hacia lo nuevo, hacia la novedad de una nueva época, en contraposición de lo antiguo. Pero también como una época que trajo consigo un nuevo principio rector: la posesión y aprehensión del mundo por la imagen. Peter Sloterdijk, inspirado en Heidegger, explica que desde esta época lo que comprendemos como Modernidad no es más que el deseo de conquista del mundo como imagen, la búsqueda de encapsular las temporalidades y la propia experiencia presente en una sintesis visual (Sloterdijk, 2004).

Lo anterior explicaría que en la carta, pasado, presente y futuro se replanteasen. Esto quedó de manifiesto de la siguiente manera: por un lado, lo aprendido del pasado se cuestionó; por otro, el presente extendió sus horizontes y la idea de transitar por el nuevo mundo descubierto se convirtió en la nueva referencia desde donde medir las relaciones con este; $y$, por último, como veremos posteriormente, el futuro se consolidó como instancia de especulación e ilusión de encontrar riquezas y un mejor porvenir, en un "más allá" o "más adelante" a perseguir, por más utópico que fuese.

Como establecen los párrafos analizados, las respuestas originarias del pasado desde ese momento debían ser respondidas por la propia experiencia

22 Se podría afirmar que esta carta puede ser una primera crítica oficial en el siglo XVI, desde el corazón de un Estado, del canon que habían impuesto y reflotado intelectuales y religiosos desde el siglo $\mathrm{XV}$ sobre los antiguos, tensión que quedó de manifiesto durante gran parte de este siglo. Anthony Grafton (1995) exhibe la manera cómo se utilizaba a Plinio y Heródoto para establecer los prototipos presente, por el propio más allá descubierto, el cual, a la vez, funcionaba como futuro:

(...) tuvieron necesidad, buscando las islas del propio nascimiento de la especiería, de dar una vuelta por deyuso deste nuestro hemisferio a todo el mundo primero que las hallasen y acá volviesen rodeando y travesando y pasando muchas veces debajo del amplísimo paralello. Pues como esta navegación sea tenida por admirable, y jamas en tiempo alguno desta nuestra edad ni menos de las edades pasadas de nuestros mayores no haya seido, no solamente hallada otra semejante, pero ni aun tentada por persona alguna; determiné de escribir a vuestra Reverendísima Señoría (...) [Elcano] Este capitán y marineros recontaron al Emperador y a muchos otros todas y cada una de las cosas en este su viage acaescidas, con tanta fe y sincera fidelidad, que segun la manera de su recontamiento pareció claramente a los que las oíamos decir en todo verdad, y no ser en ello mezclado cosa alguna fabulosa; antes tenemos agora conoscimiento, y de cierto creemos ser fabulosas y cosa no verdaderas las que los autores antiguos dejaron escriptas; y que con la experiencia de los presentes pueden aquellas ser reprobadas (Transylvanus, 1522, p. 259).

La referencia a la noción de verdad, permite interpretar que la primera vuelta al mundo no sólo definió los limites planetarios en relación a la imagen de la Tierra y sus márgenes - antípoda (Moretti, 1994)-, considerando dentro de ella una perspectiva material, sino que además interpretamos expandió y replanteó la idea de "más allá" tanto en su forma ontológica -imaginaria y espiritual- como en la forma de habitar y experimentar el mundo. La nueva historicidad no podía estar apoyada en lo descrito en

para describir y legitimar diferentes lugares y pueblos; (pp. 36 y ss). Cf. Peters (2001, p. 609).

23 De acuerdo a Paul Freedman (2010), los árabes ya tenían conocimiento de dónde se encontraban las verdaderas Molucas, lo que fue tardío en Europa.

24 Respecto a la importancia de la movilidad de las islas e imaginarios en torno a ellas véase: (Benat-Tachot, 2001). 
épocas anteriores. La verdad a relatar y a periodizar tenía que estar vinculada al nuevo mundo que acababa de completarse, como también al Nuevo Mundo que acababa de develarse casi por completo, y desde el cual también se podría acceder al paraíso ${ }^{25}$.

Era la experiencia contemporánea la que era portadora de la verdad. Por tanto, era solo en este nuevo más allá que funcionaba como un delimitador y, a la vez, como un Plus Ultra, encapsulador de lo incógnito y de territorios vastos, donde el relato histórico podía seguir. Esto lo tuvo muy claro el secretario de Estado, quien utilizó las experiencias transmitidas por una serie de conquistadores y marinos para justificar este variación. Para él, la historicidad se construía en la experiencia que iba hacia Oriente pero desde América. Los nombres de Heródoto y Plinio fueron reemplazados por los de Pedro Mártir de Anglería o Hernán Cortés ${ }^{26}$.

los castellanos han hecho sus navegaciones contra el mediodía, volviendo siempre sobre la mano derecha hacia el occidente de aquella parte del termino y limite de las trescientas y sesenta leguas a la parte occidental de la isla del Fuego, por donde va echada fabricada la línea de polo a polo. E navegado en esta manera los castellanos han descubierto $y$ hallado la tierra firme, que es muy ancha $y$ espaciosa, sin le hallar fin. E han ansi mismo descubierto e hallado muchas, muy grandes e inumerables islas, riquísimas de oro y perlas. E finalmente, han agora a la postre de todo descubierto e llegado a una grandísimo cibdad llamada Timixtitan, que está muy adentro metido en la meitad de aquella tierra firme, fundada y asentada en meitad de un grande lago, al modo y manera de la cibdad de Venecia. De todo lo cual ha escripto Pedro Mártir muchas, muy grandes y muy verdaderas

25 Desde el siglo XV, la localización del paraíso en Oriente, conforme a la mayoría de los geógrafos cristianos, multiplicó las ya de por si atractivas imágenes que de India y de Asia oriental se tenían en Occidente (Freedman 2010, p. 17). El mismo autor remarca firmemente este pensamiento al señalar que Se pensaba que el Jardín del Edén, el paraíso terrenal, se encontraba en el extremo oriental de Asia. Las especias procedian de estas tierras fragantes y distantes. El olor paradisiaco y la imagen de pureza cosas por elegante manera (Transylvanus, 1522, p. 260-261).

Pero no sólo se trató de reemplazar nombres, también fue un ejercicio de ir posicionando lo relatado sobre América -referencia inmediata del nuevo más allá- como un pasado verdadero. Esto lo apreciamos en la sección en que Transylvanus narró las dificultades y batallas que debió librar la expedición de Magallanes en islas como la gobernada por el Rey Mauthan. La valentía de Magallanes y sus hombres fue comparada con la astucia de Cortés, quien unos años antes también habría tenido una batalla desigual en el norte de América:

E como Magallanes vido de aquel bárbaro se quería poner en resistencia, de no le volver las espaldas, sino pelear con él, no embargante que la gente que consigo llevaba era sin comparación mucha menos que la que su contrario traía, porque ellos no eran, segun dicho es, mas de cuarenta españoles, y los indios contrarios eran mas de tres mil. E hizo luego sacar de los bateles los tiros de artillería y ponerlos en tierra a la ribera del mar, y animando a sus españoles les dijo ansi: no os espante, hermanos mios, que Dios será nuestra ayuda, y acordaos que pocos dias ha vimos y oímos que capitán Hernan Cortés vencio por veces en las partes del Yucatan con doscientos españoles a doscientos y a trescientos mil indios (Transylvanus, 1522, p. 281).

De alguna manera, esta conectividad temporal y espacial fue parte de una velocidad nueva. El secretario de Carlos $\mathrm{V}$ fue uno de los primeros personajes modernos que dejó hizo patente esta conciencia sobre la necesidad de la

$y$ eternidad no eran simplemente metáforas abstractas sino conceptos vívidos que impregnaron la tradición geográfica. (pp. 108-119 y ss).

26 Para Grafton (1995): And the sixteenth-century intellectual who set out to depict the New World could find enough ingredients in the classical heritage to produce a kaleidoscopic variety of juxtapositions and compounds (p. 42). 
aceleración de la historia por medio de la conexión y superposición de lo ocurrido en el Nuevo Mundo -en desmedro de lo antiguo-, con el nuevo mundo que venía de ser descubierto.

\section{Nuevo Orbe, nuevos monstruos}

a future that would not be monstrous would not be a future; it would already be a predictable, calculable, and programmable tomorrow. (Derrida \& Weber, 1995, p. 386). ${ }^{27}$

La transformación de los límites espaciales también trajo consigo un cuestionamiento. $\mathrm{O}$, dicho de otra forma, un develamiento de las percepciones sobre lo que se pensaba que conformaba el mundo. Los significados de las imágenes que se tenían sobre las cosas, personas y naturalezas hasta el descubrimiento del estrecho de Magallanes debieron modificarse, fueron trastocadas, y entraron en disputa o en una redefinición (Davies, 2016), instaurándose una nueva consciencia basada en la experiencia de la circulación por el globo ${ }^{28}$. El Estrecho funcionó no solo como un pasaje o una referencia territorial que unía mundos, sino que su importancia radicó en que se forjó desde este descubrimiento una consciencia sobre cómo pensar el (nuevo) mundo en su conjunto (Tierra), así como también sobre cómo experimentarlo comercial e imaginariamente. Desde este acontecimiento, observamos un despertar de lo que entendemos como conciencia-mundo ${ }^{29} y$ denominamos a dicho Estrecho, por la complejidad de roles que cumple, como un pasaje-mundo.

Esta proliferación de nuevos significados necesariamente forzó a que quedaran marcadas o diferenciadas las interpretaciones, y a dejar trazadas las territorialidades de cada una de ellas. Como señala Sloterdijk (2004), la edad moderna y la Modernidad pueden caracterizarse inequívocamente por una restructuración radical de las relaciones de inmunidad ( $p$. 478). La conformación de la esfera produjo que

27 Citado por (Steel, 2012, p. 347).

28 Para Rodríguez Salgado (1996), a inicios del siglo XVI los hombres modernos tenían varias consciencias $e$ identidades. (p. 51).

29 Gruzinski (2011) plantea la siguiente definición al respecto, $\mathrm{Au}$ XVI siècle, des géographes, des missionnaires, las relaciones de inmunidad entre los objetos y personas dejaran de ser lo que eran, es decir, las fronteras, las formas de protegerse, etc., se expandieron $\mathrm{y} / \mathrm{o}$ fueron sustituidas por nuevos referentes o por nociones imaginadas e incógnitas nuevas y diferentes a lo que desde la Antigüedad se había propuesto.

Desde este razonamiento se entiende que la apertura de la Modernidad como época fuera replantear, entre otras cosas, el tema de la propia alteridad, la imagen del otro. La misiva expone esto por medio de diversas preguntas y cuestionamientos sobre lo que los antiguos habían referido en relación a ciertos moradores de lugares lejanos a Europa. El escrito dejó en evidencia que las imágenes sobre ciertos otros, muchas veces descritos como monstruos, no eran válidas, puesto que la nueva experiencia de circulación había demostrado su inexistencia.

Quien es el que creerá ya de aquí adelante que hay los Monoscellos (o Stipadas), Spithameos (Pigmeos) y otros semejante, que son mas monstruos que hombres, que los antiguos escriptores nos dejaron escripto que había, como veamos que los castellanos navegando contra el mediodía y volviendo hacia el poniente, $y$ los portugueses yendo hacia el oriente pasando muchos grados adelante del trópico de Capricornio, hayan verificado, descubierto y hallado tantas y tan extrañas tierras; y finalmente, estos nuestros españoles que en esta nao agora volvieron, habiendo dado una vuelta al universo orbe, nunca hayan topado, visto ni podido saber ni menos oir en todo lo que han andado, que agora $\mathrm{ni}$ en tiempo alguno haya habido ni haya los semejantes hombres monstruosos? (Transylvanus, 1522, p. 259).

Con estas interrogaciones, el escrito de

des représentants des couronnes européennes, des explorateurs et d'innombrables aventuriers prennent conscience du fait qu'ils évoluent au sein d'espaces aux dimensions gigantesques, infiniment extensibles et qui semblent voués á se confondre avec le globe tout entier (p. 181). 
Transylvanus deseaba poner en jaque nuevamente la veracidad del contenido de los eruditos antiguos $^{30}$ y marcar, peyorativamente, que lo que se había escrito no era algo más que fabuloso ${ }^{31}$. Las líneas que prosiguen a nuestra cita explicitan aún más esto:

Ansí que todo lo que los antiguos cerca desto dijeron se debe tener por cosa fabulosa y falsa, y que como lo oyeron sin saber la verdad dello lo escribieron, $y$ ansi han venido las semejantes fábulas y mentiras de muy antiguo de unas manos en otras y de un autor a otro, sin haber alguno cierto no auténtico autor dello. Mas porque yo que tengo agora que dar una vuelta en mi relación a todo el mundo no sea visto en el exordio y principio de mi recontamiento remontarme mucho a las antiguas y falsas opiniones de aquesta cosas, baste lo que cerca desto de suso he dicho, $y$ con tanto vengo a lo que hace al caso (Transylvanus, 1522, p. 258-259).

Ahora bien, cabe precisar que la lectura sobre la alteridad estuvo marcada por la circulación inspirada en el comercio $^{32}$. Los monstruos esperados no fueron encontrados porque la expedición guiada por Magallanes, al menos hasta su muerte, negoció y logró definir desde una esperanza comercial la imagen del otro en cada uno

30 Davies observa un cambio relevante luego de esta expedición: The circumnavigation also marked an ontological seam between two discourses from classical antiquity for understanding human cultural and physical variation: the discourse of monstrous peoples, who fell beyond the purview of regular humanity and civility; and the discourse of contingent human variance in temperament, appearance and capacities in relation to local climatic conditions (Davies, 2016, pp. 7-8).

31 Para Francesca Leoni (2012) los eruditos occidentales no complejizaron lo suficiente el tema de los monstruos. En efecto, en algunas culturas lo que para Occidente era monstruoso, para ellos no lo era. Se construyó un canon universal de los monstruos.

32 Las historias de negocios tienden a subrayar lo tecnológico o lo conceptual, el "cambio de paradigma" de los avances, pero son las modas, los caprichos, y las maravillas los que estimulan la imaginación, incluida la de los inversores $y$ las de quienes asumen los riesgos físicos y financieros (Freedman, 2010, p. 166). de los lugares del itinerario ${ }^{33}$. Las ganancias que se esperaba obtener del eje comercial que había entre China y Malaca fueron las que definieron en parte esta nueva alteridad que acusamos ${ }^{34}$. Malaca era descrita en la carta como el principal puerto de todas las ferias y contratación oriental, en tanto que China se destacaba como una suerte de Alemania, por el orden y los colores de sus personas.

E aun procediendo mucho mas adelante han pasado y llegado hasta entrar en aquel grandísimo seno del mar en cuyas riberas y costas son los pueblos de los Sinas, a quien agora en aquellas partes llaman Schinas, la gente de los cuales es blanca y asaz politica y urbana, de la manera y forma como nuestra Alemania, e creése que las tierras y provincias destos Sinas se extienden y llegan hasta los Seras y Schitas y Asiáticos. (Transylvanus, 1522, p. 261).

Pese a esta búsqueda de similitud entre las Schinas y Europa, la reflexión propuesta fue más profunda. El secretario de Carlos V comprendió que la idea de monstruo tenía nuevos protagonistas $^{35}$. Para él, no eran las culturas ${ }^{36}$ desconocidas las que debían ser asociadas a lo monstruoso (Mittman, 2012, p. 48) 37 $^{37}$ sino que más bien debían ser las propias empresas

33 Freedman comenta que: La única nao sobreviviente, la Victoria, trajo de vuelta alrededor de 53.000 libras de clavo, suficiente para producir un beneficio teórico del $2500 \%$ repartido entre el puñado de supervivientes, los inversores y la corona española (Freedman, 2010, p. 240).

34 En referencia a las expectativas etno-geográficas generadas por los monstruos, ver (Davies, 2012. p.108).

35 Según Davies (2012), Transylvanus consideraba que la monstruosidad era humana y que, a la vez, era muy complejo para la comprensión el hecho de separar si eran nacimientos malos, gente inusual o algo fabuloso. (p.110).

36 Jerome Cohen (1996) explica que the monstrous body is pure culture. A construct and a projection, the monster exists only to be read [and] signifies something other than itself. (p. 4).

37 Para una discusión sobre los conceptos de bárbaro y razas durante ese tiempo, en relación al mundo antiguo, ver (Smith, 2009). 
europeas de conquista, las que, con tal de obtener réditos ${ }^{38}$, eran capaces de aventurarse a tierras desconocidas asumiendo peligros, muchas veces injustificados, en lo que se pensaba era aún un mundo nuevo e incógnito ${ }^{39}$ :

y que solo dos cosas hay notables entre ellos [orientales], conviene a saber, grandísima paz y quietud y mucha abundancia de especería, la una de las cuales (que es la paz y quietud, y el mayor y mas saludable bien de todos los que en este mundo hallarse pueden) ha desterrado destas nuestras partes la grandísima maldad de los mortales echándola en aquellas Molucas de que aquella gente pacífica usa. La otra, empero, que es la especería nos contriñe lo uno por la grandísima avaricia que tenemos, y lo otro por nuestra insaciable gula a que hayamos de la ir a buscar en aquel incognito y nuevo mundo, pasando por tantos peligros y discrimenes de la vida. (Transylvanus, 1522, p. 291).

Lo monstruoso era el nuevo efecto ${ }^{40}$, las empresas y la inconmensurabilidad que se esperaba abarcar, como también creemos que lo era la consciencia de saber todo esto. Esto explicaría el cambio en la idea de monstruo y en los significados de la monstruosidad desde esta época a la cual apuntamos (Freedman, 2010, p. 120 y ss), lo que también debe ser entendido como un cambio en la idea de Humanidad -en

38 Paul Freedman (2010) se refiere a las miradas en contra que tuvo el tema de las especias, por ejemplo con los protestantes: El deseo por las especias no es en sí mismo perverso, pero lo que es desproporcionado para el placer que aportan es el esfuerzo y la concentración que suponen su explotación (p. 184).

39 Sloterdijk (2004) presenta una idea de cómo funcionaba esta ilusión: En sus nuevos y eficientes medios -libro popular, libro de viaje, novela, utopía, hoja volante, globo y mapamundi-, la memoria del Nuevo Mundo real y de sus posibles variantes genera un régimen posmetafísico de deseo, que ve su cumplimiento, si no en la proximidad más próxima, sí en una lejanía accesible. Con él se pone en marcha una especie de selffulfilling wishful thinking, que enseña a poner rumbo, fantástica y realmente a la vez, a mundos remotos y a sus riquezas, como si su presencia tanto existencia como forma de imaginarla- como señala Jeffrey Andrew Weinstock:

What this means is that to redefine monstrosity is simultaneously to rethink humanity. When our monsters change, it reflects the fact that we-our understanding of what it means to be human, our relations with one another and to the world around us, our conception of our place in the greater scheme of things-have changed as well (Weinstock, 2012, p. 356) ${ }^{41}$

Esta monstruosidad fue parte de esta nueva conciencia-mundo, la que quedó expresada en una diversidad de formas -no siempre coherentes ni estéticas-, representativas del movimiento ilimitado y sinérgico que se produjo a nivel planetario desde esta época, en la que comenzaron a conectarse personas y objetos en función de ambiciones personales y colectivas ${ }^{42}$. Gran parte de esta monstruosidad fue trasladada hacia la zona sur del continente americano (Davis, 2016, p. 174 y ss), y estuvo proyectada y ligada a la reposición de la idea de las zonas climáticas y a la idea de fin de mundo. Y fue el develamiento del estrecho de Magallanes lo que permitió estos cambios.

\section{El Estrecho como constructor de territorialidades}

Desde que fue atravesado oficialmente en $1520^{43}$, el estrecho de Magallanes se transformó

barruntada en la lejanía fuera ya una promesa de su alcance (p. 759).

40 Mittman (2012) indica sobre los monstruos que: Rather, I submit, the monster is known through its effect, its impact (p. 47).

41 Cf. Besse (2003, p. 19).

42 Las palabras de John Block Friedman (2012) son sugerentes al respecto: Thus to be spiritually or politically wrong was to be monstrous ( $p$ 32). En cuanto a los aspectos despreciables e inadmisibles de la naturaleza humana, y a la situación híbrida del monstruo, véase: (Leoni, 2012, p. 230).

43 Para una mirada panorámica sobre este descubrimiento y los efectos territoriales en América y Chile en el siglo XVI, ver los trabajos de (Martinic, 1999); (Moreno, 2013). 
en una territorialidad de referencia que sirvió para reconfigurar y crear otras territorialidades o imágenes territoriales. En este sentido, interpretamos que el Estrecho devino en una fabrica de Modernidad, al estar involucrado directamente en una serie de modificaciones respecto a las imágenes del Mundo. De inmediato, y considerando los antecedentes presentados, planteamos una serie de preguntashipótesis: ¿cómo desde un lugar de paso, que a escala global puede ser considerado como minúsculo, se pudieron terminar de esbozar una serie de territorialidades de gran escala, como la Tierra, el Nuevo Mundo y lo Incógnito? ¿Cómo la imagen de un territorio, poseído jurídicamente pero no habitado durante años por parte de los europeos, funcionó como una máquina para crear más imágenes territoriales?

A gran escala, como se ha visto, este pasaje-mundo intervino en la constitución de la noción de la Tierra. En efecto, casi no existen representaciones cartográficas sobre este que no estén asociadas exclusivamente a imágenes sobre el planeta o mapamundis en el siglo XVI. Ahora bien, no sólo debemos pensar en una nueva Tierra, sino en un nuevo mar y estrellas que fueron insertándose dentro de un juego geopolítico que forjó cartografías particulares. La disposición geográfica del estrecho de Magallanes fue considerada como un eje conector de elementos del mundo natural, geográfico y estelar desde aquellos años, como lo muestra la imagen construida por Battista Agnesse hecha en 1544 en Venecia, a petición de Carlos V. Desde este paso emana, o se dibuja la conjunción del resto de elementos y de diferentes mundos: se legitima la territorialidad nueva de cada uno de ellos. Al realizar un "zoom", en el centro de la imagen, la cara de la Tierra tiene al Estrecho como un posibilitador de esta conectividad que trasciende lo territorial, que también atrapa al zodiaco y a energías como seres vivos de diversa procedencia.

En relación a la veta oceánica, fue el Estrecho el que permitió la cimentación final del territorio del Océano Pacífico ${ }^{44}$, y de un nuevo cielo que dirige y marca estas territorialidades.

44 Cf. Rainer Buschmann (2014).

45 La cursiva es nuestra. La importancia de las zonas tórridas
De hecho, en la carta de Transylvanus el Océano Pacífico también se muestra como parte de lo incógnito que fue sobrepasado:

Acabado pues de pasar todo aquel estrecho, que juran y afirman que les duró por espacio de mas de cien millas italianas, y llegados al mar ancho del sur, el cual creo yo que jamas recibió en sí ni navegaron por él otras algunas naos, salvo estas nuestras tres españolas que en él entraron, viendo Magallanes que la tierra firme (que a la mano derecha dejaban) daba vuelta y se volvia hacia la parte septentrional, dejó la dicha tierra a mano derecha y enderezó su viage contra aquella parte de entre el occidente y el septentrion por aquel muy espacioso $y$ incógnito mar con intención de ir navegando por aquella derrota hasta se tornar a poner dentro de la tórrida zona, $e$ ir de aquella manera por el occidente a salir al oriente (Transylvanus, 1522, p. 271-272) ${ }^{45}$

En términos continentales, este pasajemundo también fue determinante para modelar a la propia América, es decir, la propia construcción visual del Nuevo Mundo. Esta importancia se mantuvo durante décadas después de que se atravesara en 1520, como también desde antes de su descubrimiento (Besse, 2003, p. 53). Esta última afirmación la sostenemos en el hecho de que una serie de actores -marinos, cartógrafos, matemáticos, políticos-, ya estaban al tanto de la existencia del Estrecho antes de su descubrimiento. Por tanto, descartamos una dimensión de lo fortuito ${ }^{46}$. En efecto, en varias cartografías la parte sur de América, por el Pacífico, ya aparece dibujada antes de que se completara su paso. Esto se aprecia con mayor certitud desde la aparición de las cartas de Vespucio y de mapamundis como el de Waldseemuller en 1507.

Esto no nos parece contradictorio respecto a la valoración del descubrimiento del Estrecho y los cambios que produjeron desde él. Era

es analizada por Nicolás Wey Gómez (2008).

46 Cf. Richardson, (2003). 


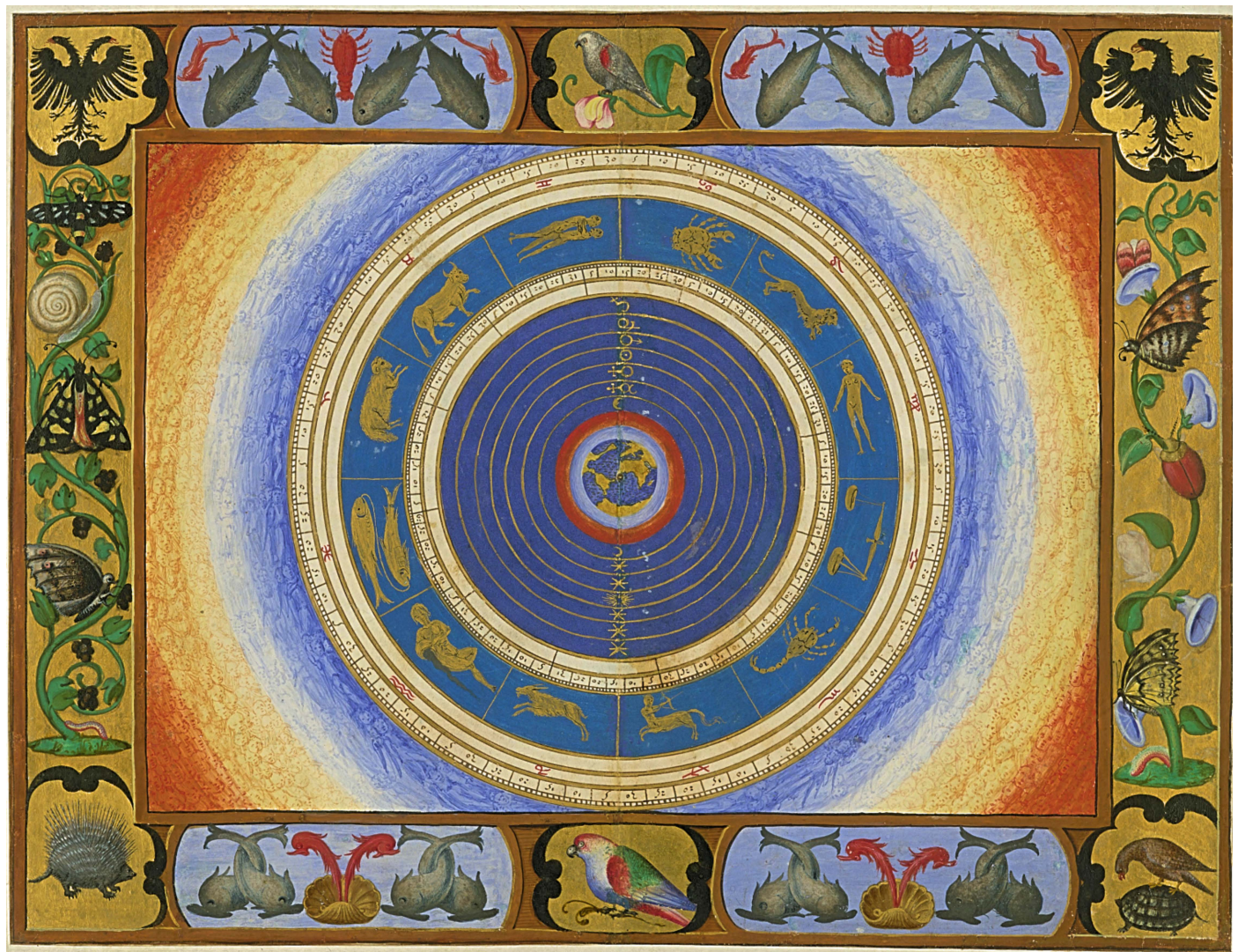

Fig. 1. Atlas de Battista Agnesse, Venecia, 1544. ${ }^{47}$

necesaria la experiencia y la legitimidad política para que existiese el reconocimiento como tal. De hecho, el conocimiento previo del Estrecho lo dejó de manifiesto el propio Magallanes cuando fue a convencer a la corte de que aprobara su travesía ${ }^{48}$. La carta de Transylvanus explica cómo, con mucha seguridad, Fernando de Magallanes junto a su socio Cristóbal de Haro, propusieron al Rey que enviase sus naos y armadas por la parte de los mares de occidente, bajando al otro hemisferio (Transylvanus, 1522, p. 263). El Rey y sus consejeros consideraron inicialmente esta idea como dificultosa y de vanidad, debido a

la incertidumbre que habia de poder pasar y navegar por las partes occidentales hasta allá. Ca creian que la ingeniosa

47 Gentileza John Carter Brown Library: http://jcb.lunaimaging.com/luna/servlet/ detail/JCB 1 1 1793 2740002:-Zodiac?qvq=q:agnese $\& \mathrm{mi}=1 \& \operatorname{trs}=15 \# \quad$ (revisado el 15 natura, que todas las cosas constituyó con suma providencia, habia por ventura dejado cerradas y distinguidas las partes orientales de las occidentales, en tal manera que no se pudiese navegar ni pasar de las unas a las otras partes (Transylvanus, 1522, p. 263).

El documento se explayó aún más en esto. De hecho, comentaba que la duda de la Monarquía radicaba en que por el norte de América ya se había intentado encontrar un paso de manera infructuosa, por ende, no era extraño pensar que lo mismo podría suceder al sur. No obstante, de acuerdo a las informaciones que manejaban ambos portugueses, y como quedó explicitado en la carta, ellos sabían que había un pasaje por el hemisferio

diciembre de 2016).

48 Sobre la ruta de Magallanes y las discusiones en torno a qué territorios habría realmente navegado, ver (Nunn, 1934). 


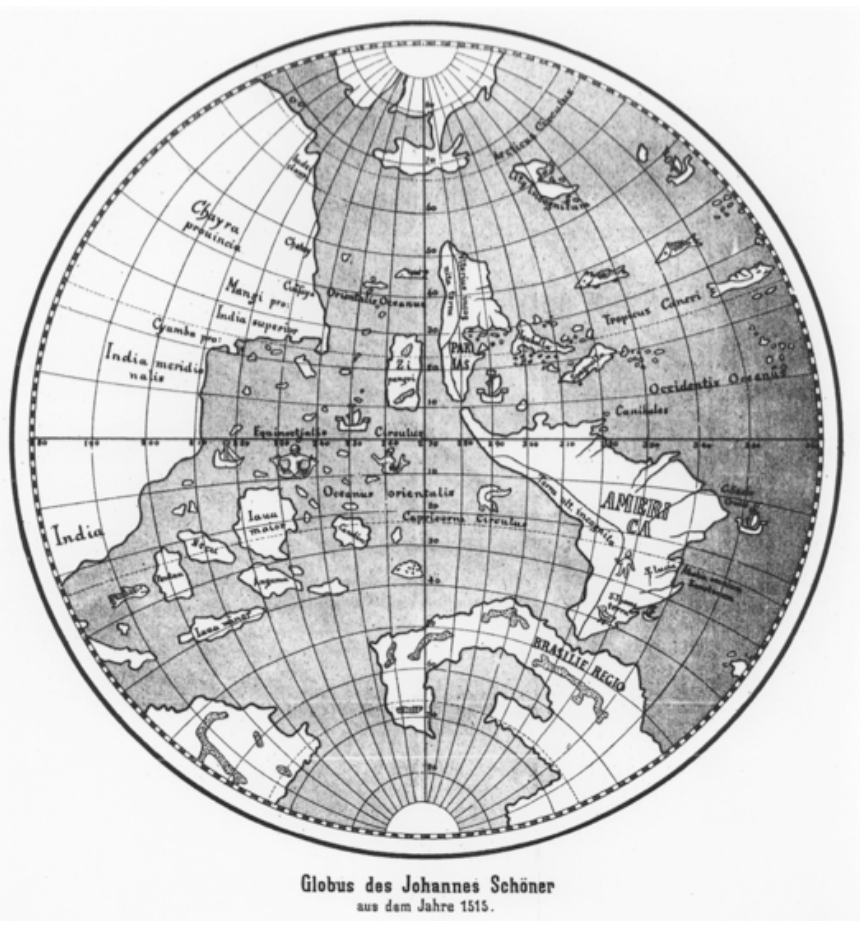

Fig. 2. Globo de Johann Schoner, $1515 .{ }^{49}$

verificase la tierra firme delante de lo que estaba sabido y descubierto y que fuese procediendo siempre contra el mediodía hacia la parte austral hasta ver si tenia cabo y fin aquella tierra firme, o hasta que hallase el gran pasage por donde se pudiese navegar y pasar al otro mar del sur, por el cual pudiese ir buscando las islas Molucas hasta las hallar (Transylvanus, 1522, p. 264).

Respecto a la influencia posterior del Estrecho en los trazos del Nuevo Mundo, esto sucedió de diversas formas y escalas. El mapa portulano sobre el Océano Pacífico del genovés Battista Agnese -parte del mismo atlas que la imagen 1- ayuda a observar la referencialidad que tuvo el Estrecho respecto a los esbozos cartográficos de América en el siglo XVI.

En éste, el estrecho de Magallanes se presenta como la mayor puerta de entrada para insertarse en dicho océano. Ahora bien, este mapa exhibe una lectura

sur $^{50}$. Finalmente la expedición se autorizó, pero no fue financiada por la Corona ${ }^{51}$ sino a costa de ambos navegantes. Con todo, resulta sorprendente la claridad expuesta por ambos portugueses sobre el conocimiento de un paso por el sur de América y que, aun así, esto no haya sido considerado:

hizo capitán dellas a Hernando de Magallanes, mandándole que costease y

49 Franz von Wieser, Magalhaes-Strasse und Austral-Continent. Auf den Globen Johannes Schaner. Beitrage zur geschichte der Erdkunde im XVI. Jahrhundert, Innsbruck, 1881. Visto en: http://cartographic-images.net/Cartographic_Images/328_ Schoner_1.html (revisado el 15 de diciembre 2016).

50 Esto quedó expuesto posteriormente por algunos testigos, como el célebre Bartolomé de las Casas, en su Historia de las Indias. El religioso se encontraba en Valladolid en 1518 cuando Magallanes presentó a los consejeros de Carlos V su idea de encontrar un estrecho para pasar a Asia. Así lo dejó expuesto en su libro: Por este tiempo, en Valladolid, vino huyendo de Portugal, o escondidamente por cierta queja que del Rey tenía, un hombre marinero, o al menos sabía mucho de la mar, llamado Hernando de Magallanes, que en portugués se decía, Magalhaes, y con él un bachiller, o que se decía bachiller, que tenía por nombre Rui Faleiro, a lo que mostraba ser, grande astrologo, pero los portugueses que va más allá de la simple presentación de las costas de América. En primer lugar, se infiere que la escala resulta ser un proceso complejo de construcción que requirió de información de viajeros transmitida desde una de las cortes, lo que nos devela una conexión narrativa (Padrón, $2004)^{52}$ y experiencial entre los mercantes, marinos, mediadores (cartógrafos o cosmógrafos) y príncipes que encomendaban estos trabajos.

afirmaban tener un demonio familiar y que de astrología no sabía nada. Estos se ofrecieron a mostrar que las islas de Maluco y las demás, de que los portugueses llevan a Portugal la especería, caían o estaban dentro de la demarcación o partición que se había comenzado, aunque no acabado, entre los reyes de Castilla, católicos, y el rey D. Juan de Portugal, el segundo, de las partes australes y occidentales, y que descubrirían camino para ir a ellas fuera del camino que llevaban los portugueses, y este sería por cierto estrecho de mar que sabian (Casas, 1876, pp. 376-377).

51 De acuerdo a Freedman (2010), Magallanes fue financiado por los Fugger. (p. 240).

52 A modo comparativo con la Tierra Australis, Hiatt (2008) comenta que: the process was not that of the formation of grandiose embellishment from a kernel of truth, but rather of the conjunction of theory with narrative (p. 225). 


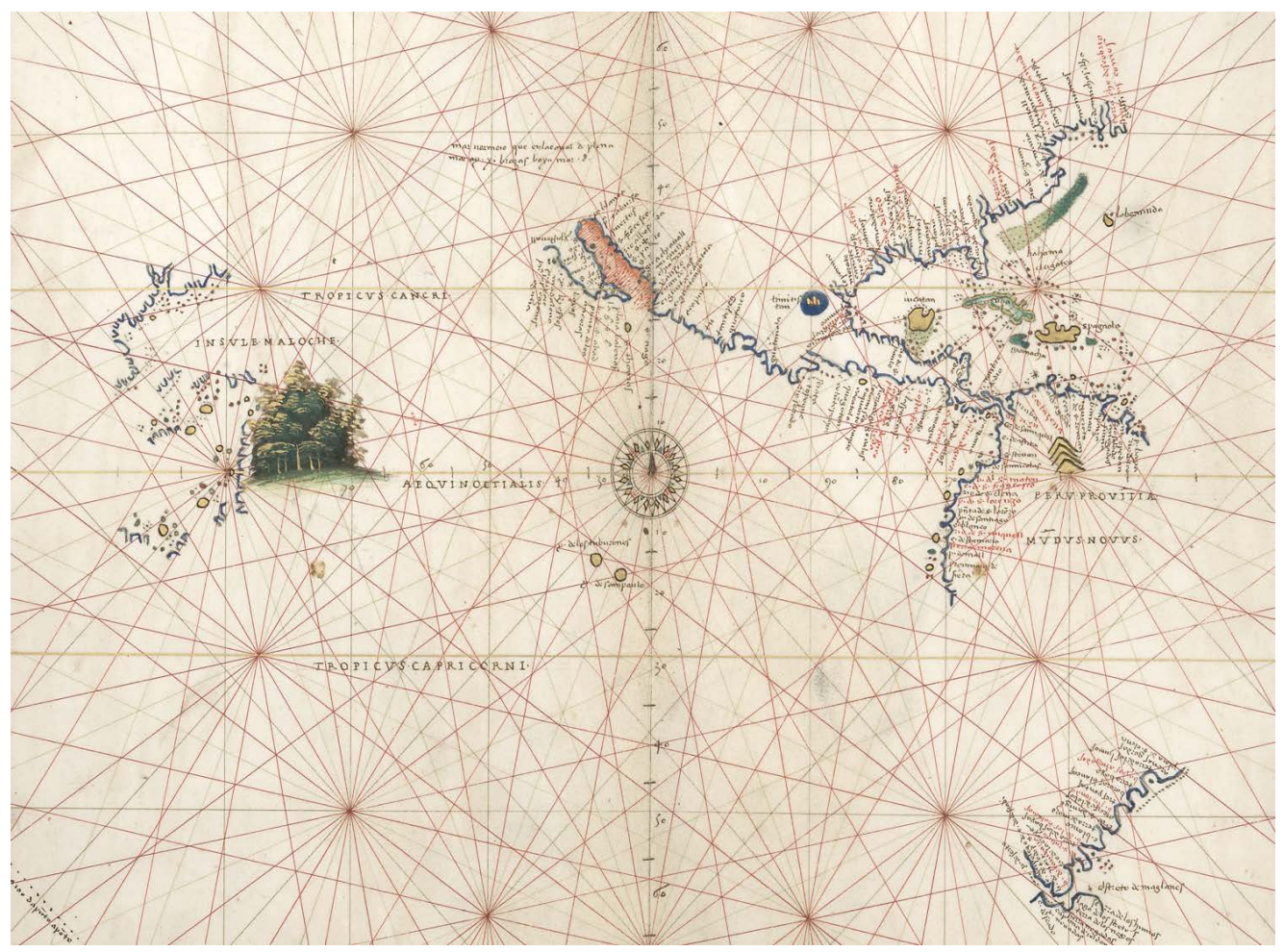

Fig. 3. Portulano Battiste Agnese, Venecia 1544. ${ }^{53}$

En segundo lugar, resulta llamativa la concepción territorial expuesta en el portulano, la que tuvo como objetivo notificar los lugares de relevancia estratégica en desmedro de otros, como es el caso del propio territorio de Chile -territorio más próximo al Estrecho. Los españoles en ese tiempo llevaban ya casi tres años instalados -desde 1541- y ya habían transferido informaciones sobre las formas geográficas y eventualidades ocurridas en dichas tierras (la parte brasileña pertenecía a Portugal e inferimos que por ello se omitió) ${ }^{54}$. Probablemente, las informaciones sobre estos lugares aún no importaban por no haber sido encontradas grandes riquezas o por ser muy sucintas las noticias, las que no habrían logrado impactar y circular mayormente. De hecho, esto confirma que desde esos años se impuso una política relacionada a los intereses comerciales

53 Gentileza Library of Congress: https://memory.loc. gov/intldl/awkbhtml/kb-1/kb-1-1-3.html (revisado el 15 diciembre 2016).

54 Para Hiatt, la conjunción de la tierra incognita con el Nuevo Mundo creó una nueva técnica para construir mapas: They y geopolíticos. Las tierras de Chile no se podían comparar con las del Perú, que sí tenían grandes riquezas y, por tanto, aparecieron esbozadas. Ahora bien, el hecho de no aparecer no significó no existir. Creemos que el territorio sólo se fue develando en la medida que fue conectándose con los sucesos que le importaban al Perú y, por ende, a España.

\section{DE LO INCÓGNITO A LAS TERRITORIALIDADES DEL SECRETO}

(...) the blank space of terra incognita invited an efflorescence of representation: a flourishing of images, but also the flourishing of the idea of the unknown southern land, with all its possibilities, mirror of the Old World, mimic of the new (Hiatt, 2008, p. 225).

began to fill unknown lands with pseudo-topographical representation, imitating the forms of the known world, fabricating coastlines and interiors, even place-names (Hiatt, 2008, p. 186). 


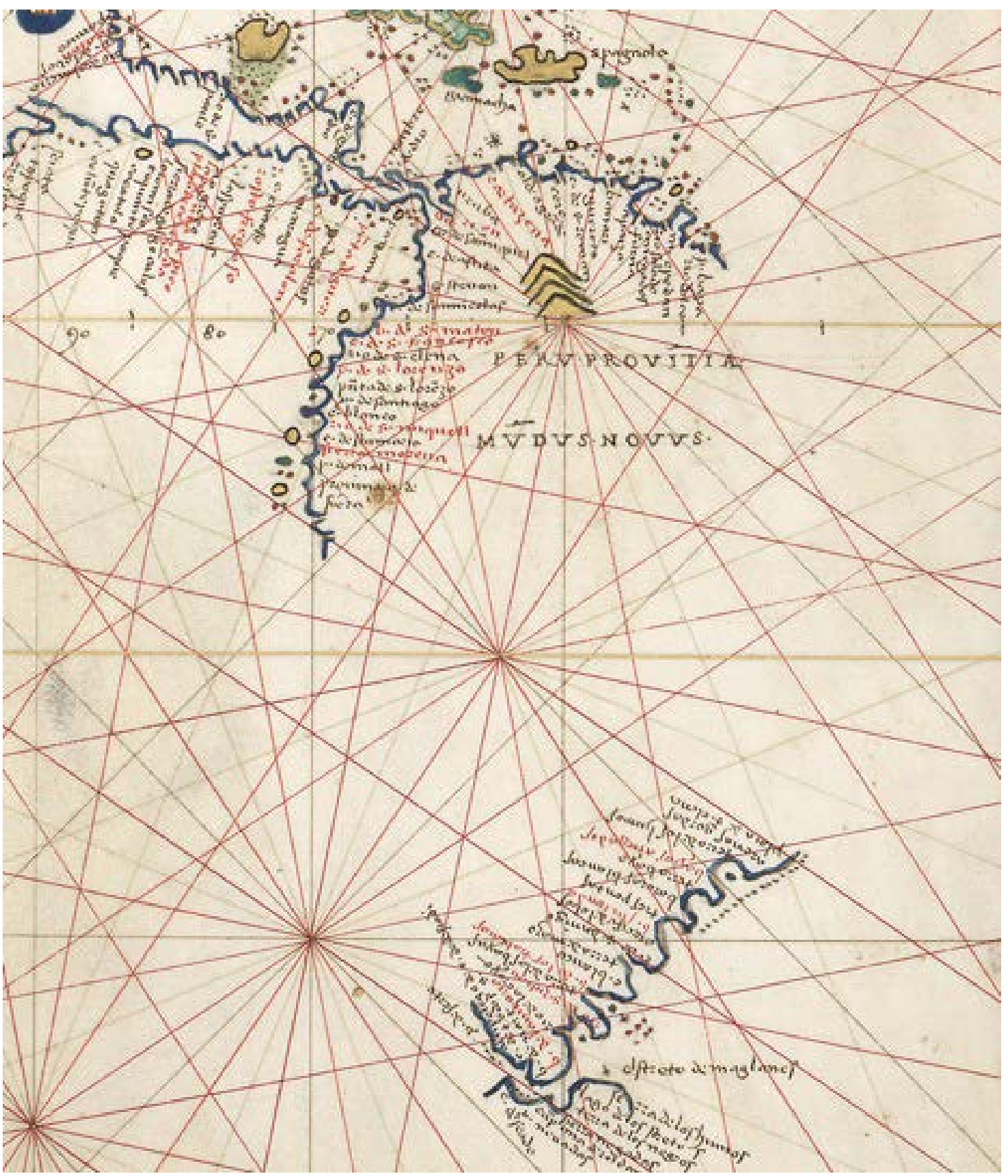

Fig. 4. Detalle mapa Portulano Battiste Agnese, Venecia 1544

Desde el principio de su carta, Transylvanus estableció una relación muy próxima entre el nuevo mundo develado y la idea de incógnito. En efecto, lo presentó como si se tratase de una misma territorialidad, siempre abundante y con proyección de futuro.
Por tanto que les rogaba y amonestaba a todos, y mayormente a aquellos en los cuales no era amortiguado el generoso ánimo y corazón de españoles, que considerasen quien eran y se sufriesen un poco; y pasasen con igual corazón y esfuerzo lo que les 
quedaba del invierno, y que tuviesen por cierto que tanto mayor gloria y mayores galardones, premios y mercedes recibirian cuanto con mayores trabajos descubriesen y hallasen para el Emperador, que los había enviado a aquel nuevo y incógnito mundo lleno de riqueza, especierías y de oro (Transylvanus, 1522, p. 271).

La claridad sobre ciertos lugares aún no descubiertos y legitimados políticamente nos habla de la existencia de una serie de secretos de navegación que pudieron existir en la época ${ }^{55}$, pero también de una puesta en escena del secreto como una forma de regular o catalizar las empresas de expansión comercial y conquista. En este sentido, se podría afirmar que gracias al descubrimiento del estrecho de Magallanes se terminó de instaurar desde los Estados europeos una geopolítica referida a las territorialidades del secreto, es decir, una política de Estado sobre cómo proceder sobre ciertos lugares asociados a secretos -de la tierra, riquezas, objetos poderosos, etc.- que, a la vez, proyectaban un más allá o una dimensión de lo incógnito que se debía poseer y conquistar. Las territorialidades del secreto fueron los territorios donde la imagen se podía reproducir libremente $e^{56}$, donde caben todas ellas, donde todo aún puede ser posible, especulado ${ }^{57}$. Fue la respuesta casi inmediata al cierre definitivo del mundo provocado por el Estrecho, por medio de una prolongación -respuesta- imaginaria de un más allá que funcionaba como apertura, el cual podía posicionarse en cualquier nuevo lugar, aunque posteriormente quedó enfocado principalmente en la Terra Australis. Era

55 Cf. Portuondo (2013).

56 La historicidad más directa del secreto estuvo ligada a las especias: fueron maravillosas y misteriosas -manifestaciones de los secretos y milagros del mundo junto con los santos, los animales extraños, los acontecimientos naturales extraordinarios como los terremotos, o fenómenos naturales míticos que incluyen los ríos de piedras o las tierras de las tinieblas. La búsqueda para descubrir las tierras donde se encontraban las especias era práctica en un sentido económico, pero era también parte del deseo medieval de encontrar los secretos de la tierra (Freedman, 2010, p. 31); Cf. Rabasa (2012).

57 El tema de los inventos, aciertos y superposiciones dentro de una misma cartografía han sido trabajados en numerosos estudios. Uno de ellos, que toma la zona de la terra australis y que nos permite adentrarnos en ello, es el de Chet Van el reconocimiento de que el mundo se había cerrado, pero también de que la circulación podía ser infinita a partir de una motivación intangible. Una circulación inspirada en el valor de la transacción y del auge extremadamente rápido, casi incontestable, de la experiencia real de poder circular por el mundo ${ }^{58}$. En otras palabras, la territorialidad del secreto fue un arma real que funcionó tanto discursivamente como cartográficamente por medio de la especulación de espacios -como la Terra Australis ${ }^{59}$-, con el fin de justificar las empresas de conquista o comerciales. Esto se explica, como indica Jean-Marc Besse, porque: Lo desconocido y lo conocido adquieren un valor ontológico y epistemológico equivalente (Besse, 2003, p. 147).

La motivación por los secretos siempre existieron. Sin embargo, observamos una institucionalización como objetivo político por parte de los Estados europeos sobre la existencia de estos posibles territorios desde la apertura del pasajemundo. Los secretos no sólo pertenecieron a marinos ${ }^{60}$, comerciantes o estudiosos de extrañezas o monstruosidades, como se reconoce hasta inicios del siglo XVI, sino que en adelante funcionó como una estrategia de Estado para expandirse o protegerse. Del mismo modo, los Estados se hicieron presentes para controlar o intentar encauzar el juego especulativo económico que podía afectarlos, dado el incipiente capitalismo que se acababa de posicionar ${ }^{61}$.

Desde Valladolid también hubo palabras para el secreto. En la presentación que hizo Transylvanus de ambos navegantes, destacaba la figura de Cristóbal de Haro como la de un comerciante conocedor de lo que había en China y de los secretos de la tierra, en

\section{Duzer (2007)}

58 Para Peters (2001), fue el descubrimiento de América el que instauró esta velocidad de la experiencia real: The events of 1493 mark the regular address to the formerly unknown world in the West and, with the voyages of Diaz, da Gama, and Magellan, brought too much real experience too quickly for traditional moral or epistemological opposition fully -or ever- to take its measure (p. 608).

59 Para Hiatt (2008) Tierra australis fue la representación de la especulación. (p. 225).

60 Cf. S. Davies (2016), en especial capítulo: Trade, empires and propaganda. Brazilians on French maps in the age of Francois I and Henri II.

61 Para Sloterdijk (2004), el capitalismo moderno comienza con el descubrimiento del estrecho de Magallanes, puesto que por primera vez el dinero circula a través de la totalidad del globo. 
algunas provincias orientales:

vino y se pasó de Portugal a Castilla un noble varon portugués llamado Hernando Magallanes, que había sido capitán del Rey don Manuel de Portugal y habia con sus armadas navegado, sabido y calado todas las partes orientales por los portugueses descubiertas, el cual se pasó acá a Castilla descontento del dicho Rey D. Manuel de Portugal por cierta ingratitud que con el habia el Rey su señor usado. E ansi mismo se pasó y vino a Castilla el dicho año descontento del dicho Rey de Portugal por cierta injusticia que dél recibió, un mercader llamado Cristóbal de Haro, que habia estado mucho tiempo tratando sus mercaderías en Portugal en la ciudad de Lisboa, y habia enviado muchas veces sus factores $e$ criados a aquellas partes orientales en las armadas del Rey de Portugal, e habia tenido contratacion con los pueblos de los Sinas, y sabido y sido avisado por sus factores de los secretos y cosas de aquellas tierras de las partes orientales (Transylvanus, 1522, p. 262).

Paralelamente al paso por el extremo sur de América, los secretos estaban tomando protagonismo en el norte. En 1520, Hernán Cortés estaba intentando descubrir los secretos de la tierra de Montezuma.

En esta gran ciudad estuve proveyendo las cosas que parecía que convenía al servicio de vuestra sacra majestad y pacificando y atrayendo a él muchas provincias $y$ tierras pobladas de muchas y muy grandes ciudades, villas y fortalezas y descubriendo minas y sabiendo e inquiriendo muchos

62 Ver la Segunda Carta de Relación, de Hernán Cortés. 30 de octubre de 1520 (p. 113); anteriormente, en el mismo documento, también encontramos la siguiente información: Y porque yo siempre he deseado de todas las cosas de esta tierra poder hacer a vuestra alteza muy particular relación, quise de ésta, que me pareció algo maravillosa, saber el secreto y envié a diez de mis compañeros, tales cuales para semejante negocio eran necesarios y con algunos naturales de la tierra que los guiasen y les encomendé mucho procurasen de subir la dicha sierra secretos de las tierras del señorío de este Mutezuma como de otras que con él confinaban y él tenía noticia; que son tantas y tan maravillosas, que son casi increíbles ${ }^{62}$.

Del mismo modo, se podría interpretar que la territorialidad del secreto fue una puesta en práctica del propio pensamiento utópico que se había forjado durante los primeros años del siglo XVI. Con esto nos referimos puntualmente a la obra de Tomás Moro, que ya había creado y consolidado una puesta en escena del tema del secreto en forma de no lugar - en 1516-, inspirado en informaciones reales aportadas por viajeros como Américo Vespucio. Esta apuesta de Moro era una modalidad que le permitía comprender y plantearle una preocupación geopolítica a su corona -cabe recordar que en 1517 es nombrado consejero de Enrique VIII- sobre una dinámica nueva que se estaba instalando, sobre decisiones políticas y estratégicas basadas en lugares imaginados pero no aprehendidos por sus propios rivales políticos. Moro marcó el camino hacia dónde debía ponerse atención y estarían las soluciones.

De acuerdo a lo anterior, proponemos que La Utopía antecedió y dio, al mismo tiempo, una performance al hecho que descubre -en su doble acepción- la Modernidad (el descubrimiento del estrecho de Magallanes). La multiplicidad de imágenes y contra-imágenes que se exhiben dentro de su mundo social permiten afirmar esto, pues encontramos algunas directrices características de lo moderno como la circulación, el idilio de riqueza, la catástrofe y la contraposición entre lo antiguo y lo nuevo. En él, no existe una ingenuidad de los objetos y lugares nombrados. Tampoco hay secretos, porque ella es el secreto.

La isla de Utopía y el camino que lleva a ella no sólo se refieren a territorios del sur de América, como se detalla en el texto, sino que se puede establecer una similitud relevante entre la geografía

y saber el secreto de aquel humo, de dónde y cómo salía. Cf. Peters (2001, p. 594). Por otra parte, como indica Alessandra Russo (2013), es importante conectar los "secretos" con los objetos dentro de esta expansión: les progres rapidez de la conquête auraient été inconcevables si les Espagnols n'avaient pas pu compter sur ces objets "stratégiques", qu'il s'agisse des panachés, des boucliers, des étendars en plumes, ou des "cartes" indispensables pour pénétrer "les nombreux secrets de la terre (p. 64). 
planteada por el inglés con la descrita por el propio acontecimiento que devela la Modernidad. Las coincidencias entre lo planteado por Moro y las geografías de la zona austral de América, vinculadas con el estrecho de Magallanes, son similares y, creemos, estaban conectadas (Onetto, 2015). En este sentido, interpretamos que las ocurrencias y desafíos que plantea La Utopía anteceden a las consecuencias posteriores que se generaron desde la propia expedición de Magallanes y Elcano. De hecho, se podría decir que La Utopía da historicidad ${ }^{63}$, una inteligibilidad previa a la travesía del Estrecho y a esa búsqueda del secreto. En contraparte, creemos que fue el estrecho de Magallanes el que permitió darle una espacialidad posible a la obra de Moro a posteriori.

La búsqueda del secreto se consolidó como una forma de actuar geopolíticamente, sobre todo, en los territorios aún no poseídos, en los cuales las historias de riqueza aún no habían sido desmentidas y la especulación actuaba sin límite ${ }^{64}$. El estrecho de Magallanes fue la puerta del más allá, pero también una territorialidad portadora de secretos. Esta disposición se prolongó a lo largo del siglo XVI, en parte, por la construcción de mitos e imaginarios en torno a ciudades de oro, como la Ciudad de los Césares o el traslado de El Dorado hacia la zona austral, pero también por decisiones políticas propias de las empresas de conquista. De hecho, el soldado Pedro de Valdivia, primer fundador de Chile, desde su llegada al territorio en 1541, no tenía otra intención que llegar a ese más allá comercial como imaginario que se podía acceder a través del Estrecho. Las tierras de Chile eran tan sólo un peldaño para llegar a dicha cima. En este sentido, no sólo es sorprendente el tema de la conciencia-mundo y modernidad que exhiben sus palabras (Onetto, 2017, p. 55 y ss), sino que además la viabilidad que da a esa otra parte del Estrecho, aún secreta:

hallo por mi cuenta que donde más S.M.

63 Cf. Hiatt (2008).

64 Para Peters (2001): If practical folk could speak thus at the turn of the sixteenth century, it is not surprising that in the course of that century their rulers should appropriate the language of secrets, including the secrets of distant places, and the desire to know them and in doing so to transform their realms into information- y Vuestra Alteza el día de hoy pueden ser servidos, es en que se navegue el Estrecho de Magallanes, por tres causas, dejadas las demás que se podían dar. $L a$ primera, porque toda esta tierra y Mar del Sur la terná Vuestra Alteza en España y ninguno se atreverá a hacer cosa que no deba; la segunda, que se terná muy a la mano toda la contratación de la especería, y la tercera, porque se podrá descubrir e poblar esa otra parte del Estrecho que, según estoy informado, es tierra muy bien poblada; y porque en lo demás no es razón yo dar parecer más de advertir a Vuestra Alteza de lo que acá se me alcanza y entiendo, como hombre que tiene la cosa entre manos, y por servir tan bien en esto a Vuestra Alteza, como ha hecho en lo demás, va el capitán Jerónimo de Alderete con determinación de hacer este servicio y meter la primera bandera de Vuestra Alteza por el Estrecho, de lo cual estos reinos recibirian muy gran contento y Vuestra Alteza muy señalado servicio ${ }^{65}$

Otra de las tantas fuentes que nos permite demostrar estas afirmaciones fue la Real Cédula escrita desde Bruselas en 1558 por Carlos V al nuevo gobernador de Chile, en donde le exigía entender los secretos que había más allá del Estrecho. El documento, entre otras cosas, expresa claramente cómo entender los secretos era una disposición, ante todo, geopolítica de conocimiento, definición de nuevos territorios y de aquellos que los habitaban.

Nuestro gobernador de la provincia de Chile, ya sabéis cómo os hemos proveído de la dicha gobernación hasta el Estrecho de Magallanes y porque nos deseamos saber las tierras y poblaciones que hay de la otra parte del dicho Estrecho y entender los secretos que hay en aquella tierra, os

gathering states, using detailed questionnaires to assemble and organize new data just as they assembled cabinets of curiosities, libraries, zoos, observatories, and botanical garden (p. 594).

65 Carta de Pedro de Valdivia al príncipe Maximiliano. Santiago, 26 de octubre de 1552, en (Rojas-Mix, 1991, pp. 180-181). 
mando que desde las dichas provincias de Chile enviéis algunos navios a tomar noticia y relación de la calidad de aquella tierra, y de la utilidad de ella y a saber y entender qué poblaciones y gente hay en ella y qué cosas se crían y qué manera de viviry costumbres tienen los que la habitan, $y$ si es isla, y qué puertos hay en ella, y de qué manera se navega aquella costa, y si hay monzones o corrientes, y a qué partes o qué curso hacen, y qué manera de religión tienen, y si son idolatrías, y qué manera tienen de gobierno, y qué leyes y costumbres, y qué minas y metales, y qué otras cosas que sean provechosas hay en la dicha tierra, y si comen carne humana, $y$ si hay o hubo entre ellos memoria de nuestra religión o de otra secta, y si tienen reyes por elección o suceden por herencia o derecho de sangre, y qué tributos pagan a sus reyes, y entendido el secreto de todo y sabido lo susodicho nos enviaréis relación de ello para que, vista, mandemos proveer en lo que toca a su población lo que viéramos más convenir, y proveeréis que se tome posesión en nuestro nombre de las tierras y provincias que caen en la demarcación de la corona de Castilla, poniendo seis cruces y señales, y haciendo los autos necesarios, y trayéndolos por testimonio, los cuales nos enviaréis con la dicha relación ${ }^{66}$.

Es cierto que este tipo de escritos eran documentos-tipo, casi cuestionarios, para elaborar posteriormente relaciones geográficas, no obstante, lo distintivo aquí es que el sondeo está hecho con base en la idea de "secreto de la tierra", es decir, lo que no se conoce y que se debe conocer, lo cual está directamente asociado con el Estrecho. La idea de secreto es paradójica en este sentido, pues invita a develar lo que vela: el secreto es una llamada al deseo de conocer. Otra cosa es que la información

66 Real Cédula al gobernador de Chile, ordenándole enviar una relación de las tierras y poblaciones que hay en una parte del Estrecho de Magallanes y que disponga que se tome posesión de ellas en nombre del Rey. Bruselas, 20 de diciembre de 1558. En AGI, PATRONATO,32, R.4, Cursivas nuestras.

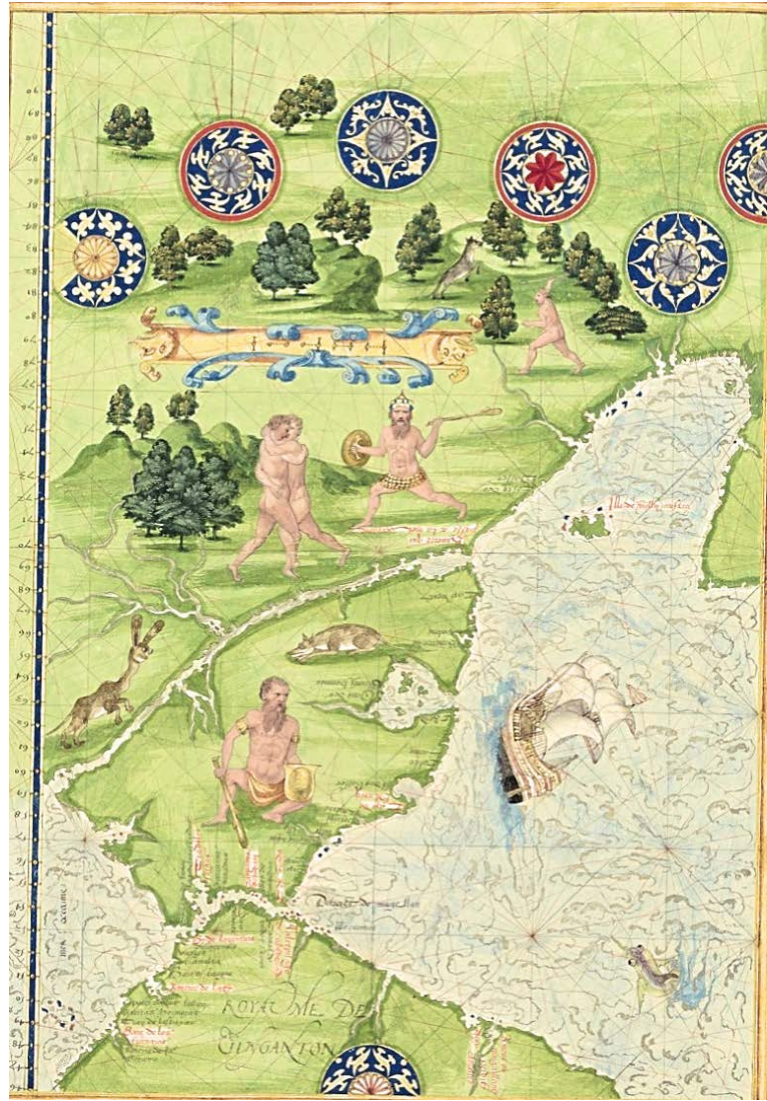

Fig. 5. Guillaume Le Testu, Cosmographie universelle, selon les navigateurs tant anciens que modernes, $1555 .^{67}$

que de allí resulte sea protegida con celo y no se comunique. Pero en todo caso, la corona necesita develar, conocer y penetrar en cada detalle. Aquí, el cuestionario de la Real Cédula es la herramienta técnica que se le da al gobernador para que lleve a cabo la conquista del secreto ${ }^{68}$

Paralelamente, en términos cartográficos, el Estrecho se convirtió en la puerta para acceder a estos territorios incógnitos y secretos. Una puerta estrecha, que en caso de estar controla podía abrir un camino a las riquezas y fertilidad esperadas. Esto operó tanto para la Monarquía Española, como en los adversarios políticos de esta. En relación a esto último, un ejemplo que resulta bastante evidente

67 Gentileza Gallica.fr: http://gallica.bnf.fr/ark:/12148/ btv1b8447838j/f88.item.r=perou (revisado el 15 de diciembre 2016).

68 Agradezco profundamente al Dr. Andrés Vélez Posada las ideas compartidas especialmente en este párrafo. 
es el trabajo del cosmógrafo francés Guillaume Le Testu quien representó esta voluntad secreta de apropiación (Martínez, 2016, p. 123). En las imágenes de su Cosmografía Universal de 1556, el Estrecho funcionó como la puerta y, a la vez, como puente que permitía la existencia de esta tierra incógnita y secreta, presentada como salvaje pero extremadamente fértil ${ }^{69}$. En la secuencia que presenta el autor las escalas desaparecen, la Terra Australis se transforma en una proyección de América, tanto desde el punto de vista territorial como imaginario ${ }^{70}$, casi tan grande como ella, y el Estrecho se vuelve en un paso impenetrable como queda representado entre el tamaño del barco y del propio Estrecho.

Este tipo de cartografías, como también otras que existieron, nos permiten aseverar que las escalas cartográficas en la época no eran sino espacios que mezclaron conocimientos y saberes que iban desde la astrología a una disposición estética de los territorios, transitados o, simplemente, imaginados ${ }^{71}$. A su vez, se podría decir que la territorialidad no era más que la imagen que se pensaba o percibía de un lugar, y donde no era necesario vivir. Bastaba sólo con especular sobre él.

\section{BIBLIOGRAFÍA}

a) Fuentes de consulta

Archivo General de Indias. PATRONATO,32, R.4.

Archivo General de Indias. PATRONATO, 49, R.9; 260.

Archivo General de Indias. SECCIÓN CHILE, Audiencia de Chile, 165, L1, L2, L3.

Carta de Relación, de Hernán Cortés. 30 de octubre de 1520.

Cartas y Relaciones de Hernán Cortés al Emperador Carlos V. Colegidas e lustradas por Pascual Gayangos, Imprenta de los Ferrocarriles A Chaix y Ca., Paris, 1866.

Casas, Bartolomé de las, Historia de las Indias, Tomo IV, Madrid, imprenta de Miguel Ginesta, 1876.

Elcano, Sebastián [1522] (2012). Carta de Juan Sebastián de El Cano al Emperador, dándole breve relación de su

69 Como examina Hiatt, la denominación terra incognita fue una continuación de una tradición meta-cartográfica asociada con el espacio de las antípodas en la Edad Media. Ver Hiatt 2008, op. cit., pp. 198 y ss.

70 Alfred Hiatt (2008) señala que el proceso de construcción de la Tierra Incógnita imita al de América. Para él, uno viaje en la armada de Magallanes y de su regreso en la nao victoria, en La primera vuelta al mundo, Madrid: Miraguano-Polifemo.

Transylvanus, Maximiliano. Relación escrita por Maximiliano Transylvanus de cómo y por quién y en qué tiempo fueron descubiertas y halladas las islas Malucas, donde es el nascimiento de la especiería, las cuales caen en la conquista y marcación de la Corona Real de España. E divídese esta relación en veinte párrafos principales. Valladolid, 5 de octubre de 1522, en Medina, J. T. Colección de documentos inéditos para la historia de Chile: desde el viaje de Magallanes hasta la batalla de Maipo: 1518-1818, Santiago: Imprenta Ercilla, Tomo I, 1888, pp. 258-298.

b) Impresos

Barrera, A. (2009). Experiencia y empirismo en el siglo XVI: reportes y cosas del Nuevo Mundo. Memoria y Sociedad, (13), 27.

Benat Tachot, L. (2001). De l'île à l'Islario: fonction et statut de l'île dans l'écriture de la conquête. En Trec, E (dir). Bout du voyage, l'ile: Mythe et réalité (56-87). Reims: Publications du Centre de Recherche VALS, Presses Universitaires de Reims.

BénatTachot, L. (2015). La Corogne et Séville: les horizons de l'expansion maritime espagnole (1492 1550), eSpania [En ligne], 22 | octobre 2015, mis en ligne le 31 octobre 2015, consulté le 20 janvier 2017. URL: http://espania. revues.org/25043 DOI : 10.4000/espania. 25043

Bénat-Tachot, L. (2001). On voit donc que la force des modèles épistémologiques modèle les regards et construit l'intelligibilité des expériences nouvelles. En Trenc, E. (coord.). De l'île à l'Islario: fonction et statut de l'île dans l'écriture de la conquête, Au bout du voyage, l'île: Mythe et réalité. Reims, Publications du Centre de Recherche VALS, Presses Universitaires de Reims.

Benites, M. J. (2013). La mucha destemplanza de la tierra: Una aproximación al relato de Maximiliano de Transylvanus sobre el descubrimiento del Estrecho de Magallanes. Orbis Tertius, (18), 19.

Bergreen, L. (2005). Par-delà le bord du monde. L'extraordinaire et terrifiant périple de Magellan. París: Grasset.

fue un proceso gradual de descubrimiento y el otro de elaboración de una fantasía.

71 Respecto a las tensiones entre lo nuevo y lo antiguo, a la curiosidad y las reticencias de dibujar lo maravilloso en los mapas, véase (Hiatt, 2008, p. 224). 
Besse, J. M. (2003). Les grandeurs de la Terre. Aspects du savoir géographique à la Renaissance. Lyon: ENS Éditions.

Buisseret, D. (2003). The mapmaker's quest: depicting new worlds in Renaissance Europe. Oxford: Oxford University Press.

Buschmann, R. (2014). Iberian Visions of the Pacific Ocean, 1507-1899. Nueva York: Palgrave.

Carrasco Manchado, A. I. (1998). Aproximación al problema de la consciencia propagandística en algunos escritores políticos del siglo XV. Revista En la España Medieval, (21), 246.

Castro, X de. (2007). Le voyage de Magellan (1519-1522). La relation d'Antonio Pigafetta \& autres témoignages. Paris: Chandeigne.

Cohen, J. J. (1999). Of Giants: Sex, Monsters, and the Middle Ages, Minneapolis: University of Minnesota Press.

Cohen, J. J. (ed.), (1996). Monster Theory: Reading Culture. Minneapolis, MN: University of Minnesota Press.

Davies, P. (2012). The Unlucky, the Bad and the Ugly: Categories of Monstrosity from the Renaissance to the Enlightenment. En Asa Simon Mittman \& Peter J. Dendle (eds), The ashgate research companion to monsters and the monstrous. Burlington: Ashgate.

Davies, S. (2016). Renaissance Ethnograpy and the Invention of the Human. New World, Maps and Monsters. Cambridge: Cambridge University Press.

Davies, S. (2016). Trade, empires and propaganda. Brazilians on French maps in the age of Francois I and Henri II. In Surekha Davies, Renaissance ethnography and the invention of the human: new worlds, maps and monsters. Cambridge: Cambridge University Press.

Dekker, E. (2001-2002). The doctrine of the sphere: A Forgotten Chapter in the History of globes. Globe Studies, 49 (50), 32-ss.

Derrida, J., Weber, E. (1995). Passages-from Traumatism to Promise. In Elizabeth Weber (ed.), Points, Stanford: Stanford University Press.

Dickson, P. (2007). The Magellan myth: reflections on Columbus, Vespucci, and the Waldseemueller map of 1507. Mount Vernon, Ohio: Printing Arts Press.

Duzer, Chet van. (2007). Cartographic Invention: The Southern Continent on Vatican MS Urb. Lat. 274, Folios 73v- 74r (c.1530). Imago Mundi, 59 (2), 193-222.

Estévez Benítez, E. (2015). Colón y la transmisión de los mitos de los pueblos monstruosos a América. Historias del Orbis Terrarum, (15).

Freedman, P. (2010). Lo que vino de Oriente. Las especias y la imaginación medieval. Valencia: Universitat de València.

Friedman, J. (2012). Forewords. En Asa Simon Mittman \& Peter
J. Dendle, The ashgate research companion to monsters and the monstrous. Burlington: Ashgate.

García Hernán, D. (2011). Guerra, propaganda y cultura en la Monarquía hispánica: la narrativa del Siglo de Oro. Revista Obradoiro de Historia Moderna (OHM), (20), 281-302.

Grafton, A. (1995). New Worlds, Ancient Texts. The Power of Tradition and the Shock of Discovery. Cambridge: Harvard University Press.

Gruzinski, S. (2011). Marges et conscience - monde: l'invention de l'Amazonie. In Louise Benat-Tachot et Bernard Lavallé (eds.), Marges et liminalité en Amérique latine, Paris, Le Manuscrit.

Hartog, F. (2003). Régimes d"historicité. Présentisme et expériences du temps. Paris: Seuil.

Hiatt, A. (2008). Terra Incognita. Mapping the Antipodes before 1600. Chicago, London: The University of Chicago Press.

Koselleck, R (1990). Le Futur passé: contribu- tion à la sémantique des temps historiques. Paris: Éditions de l'EHESS.

Leoni, F. (2012). On the Monstrous in the Islamic Visual, en Asa Simon Mittman, Peter J. Dendle, The ashgate research companion to monsters and the monstrous. Burlington: Ashgate.

Martínez, C. (2016). Relatos de viaje e imaginarios geográficos en la Cosmografía Universal (1556) de Guillaume Le Testu: apuntes para una arqueología textual. Magallánica, Revista de Historia Moderna, Vol. 2 (4), 118-135.

Martinic, M. (1999). Cartografía Magallánica. Punta Arenas: Universidad de Magallanes.

Moreno Jeira, R. (2013). El estrecho de Magallanes como antesala del Pacífico: evolución cartográfica y toponimia entre los siglos XVI y comienzos del XVIII. Anuario de Estudios Americanos. 70 (2), [En línea], Revisado 23 de jun. de 17.URL: http://estudiosamericanos.revistas.csic.es/ index.php/estudiosamericanos/article/viewArticle/601 DOI: http://dx.doi.org/10.3989/aeamer.2013.2.02

Moretti, G. (1994). Gli antipodi: avventure letterarie di un mito scientifico. Parma: Patriche Editrice.

Morton, T. (2000). The Poetics of Spice: Romantic Consumerism and the Exotic. Cambridge: Cambridge University Press.

Nieto Soria, J. M. (dir.). (1999). Orígenes de la Monarquía Hispánica. Propaganda y legitimación (ca. 1400-1520), Madrid: Dykinson,

Nunn, G. (1934). Magellan's Route in the Pacific, Geographical Review. 24 (4), 615-633.

Onetto Pavez, M. (2015). La Utopía de Moro y la Isla Grande de Tierra del Fuego, ¿Una equivalencia posible?. Magallania, 
43(1), 37-51.

Onetto Pavez, M. (2017). Temblores de Tierra en el Jardín del Edén. Desastre, memoria e identidad. Chile, siglos XVIXVIII. Santiago: Centro de Investigaciones Diego Barros Arana, DIBAM.

Oswald, D. (2013). Monstrous Gender: Geographies of Ambiguity. In Asa Simon Mittman \& Peter J. Dendle The Ashgate Research Companion to Monsters and the Monstrous. New York: Routledge.

Padrón, R. (2004). The Spacious Word: Cartography, Literature, and Empire in Early Modern Spain. Chicago: University of Chicago Press.

Peters, E. (2001). The Desire to Know the Secrets of the World. Journal of the History of Ideas. 62 (4). 609.

Portuondo Gamba, M. (2013). Ciencia secreta. La cosmografía española y el Nuevo Mundo. Madrid: Iberoamericana Editorial Vervuert.

Rabasa, J. (2012). Intencionalidad, invención y reducción al absurdo en la invención de América, Nuevo Mundo Mundos Nuevos [En ligne], Colloques, mis en ligne le 26 juin 2012, consulté le 21 juin 2017. URL: http://nuevomundo. revues.org/63440

Richardson, W. (2003). South America on Maps before Columbus? Martellus's 'Dragon's Tail' Peninsula, Imago Mundi, (55), 25-37.

Rojas-Mix, M. (ed.) (1991). Cartas de Don Pedro de Valdivia que tratan del descubrimiento y conquista de la Nueva Extremadura. Barcelona: Editorial Lumen..

Ruiz Martin, F. (1996). La proyección europea de la Monarquía Hispánica. Madrid: Editorial Complutense.

Sallamann, J. M. (2003). Géopolitique du XVIe siècle, 14901618. Paris : Points.

Simon Mittman, A. (2012). Introduction: The Impact of Monsters and Monster Studies. En Asa Simon Mittman \& Peter J. Dendle, The ashgate research companion to monsters and the monstrous. Burlington: Ashgate.

Sloterdijk, P. (2004). Esferas II. Globos. Madrid: Ediciones Siruela. Smith, Ian. (2009). Race and Rhetoric in the Renaissance: Barbarian Errors. New York: Palgrave Macmillan.

Steel Centaurs, K. (2012). Satyrs and Cynocephali: Medieval Scholarly Teratology and the Question of the Human. En Asa Simon Mittman \& Peter J. Dendle, The ashgate research companion to monsters and the monstrous. Burlington: Ashgate.

Vagnon, Emmanuelle. (2010). De la Grèce antique au voyage de Magellan. Les modèles humanistes d'Antonio Pigafetta et de Maximilianus Transylvanus. Médiévales (58) [En ligne], 20 septembre 2012, consulté le 06 juin 2017. URL: http://medievales.revues.org/5913; DOI: 10.4000/ medievales.5913

Van Duzer, C. (2013). Hic sunt dracones: The Geography and Cartography of Monsters, In Asa Simon Mittman with Peter J. Dendle, The Ashgate Research Companion to Monsters and the Monstrous. New York: Routledge.

Van Duzer, C. (2013). Sea monsters on medieval and Renaissance maps. Londres: The British Library.

Weinstock, J. A. (2012). Invisible Monsters: Vision, Horror, and Contemporary Culture. En Asa Simon Mittman \& Peter J. Dendle, The ashgate research companion to monsters and the monstrous. Burlington: Ashgate.

Wey Gómez, N. (2008). The tropic of Empire: Why Columbus Sailed South to the Indies. Cambridge: London, MIT Press.

Wieser, F. (1881). Magalhaes-Strasse und Austral-Continent. Auf den Globen Johannes Schaner. Beitrage zur geschichte der Erdkunde im xvi. Jahrhundert: Innsbruck. 